Department of Economics- FEA/USP

\title{
Spatial Distribution of \\ Logistics Services in Brazil: a \\ Potential Market Analysis
}

\author{
AdEMIR ANTônio Moreira Rocha \\ Fernando Salgueiro Perobelli
}




\title{
DEPARTMENT OF ECONOMICS, FEA-USP \\ WORKING PAPER № 2019-05
}

\section{Spatial Distribution of Logistics Services in Brazil: a Potential Market Analysis}

Ademir Antônio Moreira Rocha (ademir.rocha@usp.br)

Fernando Salgueiro Perobelli (fernando.perobelli@ufjf.edu.br)

Research Group: The University of São Paulo Regional and Urban Economics Lab (NEREUS)

Territorial and Sectorial Analysis Lab - University of Juiz de For a (LATES)

\begin{abstract}
:
The main objective of this work is to investigate the present and long-term spatial distribution of the logistics sector in Brazil. In order to do so, this study seeks to answer the following questions: i) how is the logistics sector organized in Brazil? that is, is there evidence of logistics clusters?; ii) what is the longterm perspective of this organization? The Logistics Potential Mapping Model (MapLog), inspired by Krugman's Core-Periphery Model, will serve as an analytical tool to verify the long-term spatialization of the logistics sector. The results point to a change within five decades (2015-2065) of the locational pattern of the logistics sector focused on industry but not for the logistics sector focused on agriculture.
\end{abstract}

Keywords: locational decision; logistics clusters; New Economic Geography

JEL Codes: C63; R12; R41 


\title{
Spatial Distribution of Logistics Services in Brazil: a Potential Market Analysis*
}

\author{
Ademir Antônio Moreira Rocha ${ }^{\dagger}$ \\ Fernando Salgueiro Perobelli
}

\section{$1 \quad$ Introduction}

The flows of goods between regions translate the needs of production and consumption by individuals and firms, directly influencing the economic dynamics of a region (BUTTON, 2010). According to Thomson (1974), movement by transport is desired and necessary because there is spatial heterogeneity so that none parts are capable of supplying alone all the products that people desire. That is, a varied set of goods can only be obtained by any movement between the supplier and the consumer. Logistics, in turn, is the function responsible for this movement (WATERS, 2003).

The main components of logistics - transport, storage and management - have been important elements of industrial and economic life throughout the ages, but it is only in the relatively recent past that logistics has been recognized as a relevant function in and of itself (RUSHTON et al., 2010). Technological changes in markets, institutional structures and management theory have led to new ways of thinking about logistics and associating it with the production process (BREWER et al., 2008; HUGOS, 2011). At a national level, the ability to transport goods quickly, safely, economically and reliably is now seen as vital to the prosperity and capacity of a nation seeking to compete in a rapidly globalizing economy (BREWER et al., 2008).

Achieving a high level of logistics performance is important for business profitability and for regional and national competitiveness (HEAVER, 2008), so that several operational activities of the firms, including transportation and logistics services, were assumed by third parties. Consequently, there has been increasing specialization in the management of external relations of production and control of flows, from the inputs to the final product acquired by

\footnotetext{
* The authors are grateful for the financial support of CAPES and CNPq

† PhD Candidate in Economics at University of São Paulo (USP)

Email: ademir.rocha@usp.br

₹ Full Professor in the Department of Economics at the Federal University of Juiz de Fora (UFJF) and a CNPq Scholar

Email: fernando.perobelli@ufjf.edu.br
} 
the consumer. The term "Supply Chain Management" was created in the 1970s to represent these activities ${ }^{1}$ (HALL; BRAITHWAITE, 2008).

The supply chain is a sequence of processes and flows that takes place within and between the different stages of the production chain, and that combine to meet a customer's need for a product (CHOPRA; MEINDL, 2003). The main objective of any supply chain is to satisfy customer needs and generate profit for the participating firms during the process. The term "supply chain" brings the idea of products moving from suppliers to manufacturers, moving to distributors and resellers, and reaching the end consumers. These flows, in turn, are not unique or unidirectional. By the way, a manufacturer can receive material from several suppliers and then supply their product to various distributors.

Supply chain performance is measured in terms of responsiveness (i.e., time) and efficiency (i.e., cost minimization), and will depend on the characteristics of the logistics drivers (CHOPRA; MEINDL, 2003). Logistics drivers are understood to be elements that can be used to improve supply chain performance (CHOPRA; MEINDL, 2003; HUGOS, 2011). The theorists cited define five drivers, namely: production, inventory, location, transport and information. In this study, the locational component will be highlighted.

The location refers to the geographical location of supply chain facilities, especially logistics firms. It also includes the decisions related to the activities that must be carried out in each installation. The trade-off presented here is related to the decision to centralize activities in fewer locations for economies of scale and efficiency, or to decentralize activities in many places close to customers and suppliers for faster operations. When making decisions related to location, managers need to consider a number of factors that relate to a particular location (locational factors), including the cost of the facility, the local labor cost, the skills available in the job market, the infrastructure conditions, taxes and tariffs and the proximity to suppliers and customers. Location decisions tend to be strategic because they involve large amounts of money with long-term horizons for investment maturation. In addition, the locational choice of logistics units determines, in part, the performance of several productive chains and regional and national productivity (BHATNAGAR; SOHAL, 2005; CHOPRA;

\footnotetext{
${ }^{1}$ In the literature, logistics and supply chain management are often used synonymously, although there is a subtle difference between the two. Supply Chain Management is more strategic in its nature, while logistics is more operation-oriented. Supply Chain Management deals with chain links, contracts and relationships, supplier selection, information and financial flows, as well as material flows, creating new facilities such as factories, warehouses and distribution centers. The scope of logistics is confined to the routine work of transporting and storing goods (BALLOU, 1985). It should be noted that throughout this work these terms will be treated as synonyms.
} 
MEINDL, 2003; HUGOS, 2011). Thus, the determinants of this locational decision must be better understood.

The main motivation of this study is to investigate the present and long-term spatial distribution of the logistics sector in Brazil. In order to do so, we seek to answer the following questions:

1. How is the logistics sector organized in Brazil? Or rather, is there evidence of logistics clusters?

2. What is the long-term perspective of this spatial organization?

To answer those questions, this work has as theoretical and methodological cores the approaches developed in Fujita et al. (1999), Krugman $(1991,1998)$ and Krugman \& Venables (1993, 1995), which make considerations about the location and formation of agglomerations of economic activities, to the point of developing a line of research called New Economic Geography (NEG).

Geographic space is an inherent dimension to the study of economic phenomena and its treatment involves a significant degree of heterogeneity. Economic agents and firms choose their locations based on spatial attributes, generating an unequal distribution of economic resources. This spatial differentiation can be perceived by regional disparities in the remuneration of factors of production, price levels and transport costs (CAPELLO, 2009; CAPELLO; NIJKAMP, 2009; COMBES et al., 2008). The various economic agglomerations, which reproduce the unequal nature in space, influence the way the economic system works and the regional performance itself (CAPELLO, 2009; MCCANN; VAN OORT, 2009).

Lemos (2008) argues that the advantages arising from the economic agglomerations constituted in certain regions are nothing more than agglomeration economies, which represent localized returns to scale. The existence of increasing returns to scale and the perfect mobility of resources imply the spatial concentration of economic activities. Even at an initial state they are homogeneously distributed (DUBEY, 1977; LÖSCH, 1954). Thus, there is an incompatibility between the structure of competitive markets in a homogeneous space and the formation of spatial agglomerations (FUJITA; THISSE, 2013). The hypotheses of constant returns of scales and perfect competition seem to be incapable of dealing with the empirical existence of the agglomeration of people and firms in space (COMBES et al., 2008). Thus, the association of increasing returns and imperfect competition is one way of integrating spatial aspects into economic theory. 
NEG emerged in the 1990s as a new field of research, with the purpose of revaluing and inserting geographic analysis into the economic mainstream (KRUGMAN, 1998)2. Their main concern is to explain why many economic activities are geographically concentrated. In general, the central aspect for the understanding of the spatial configuration of economic activities and their repercussions lies in the trade-off of two main types of forces: economies of scale (agglomerative force) and transport costs (repulsive force) (FUJITA; THISSE, 2013). Krugman (1991) innovates by inserting these elements in a mathematical modeling and developing for it the Core-Periphery Model.

Given that the main objective of this study is to observe the long-term spatialization of the logistics sector in Brazil, the Core-Periphery Model will be the basis for the development of the Logistics Potential Mapping Model (MapLog).

In addition to this introductory section, this article is divided as follows. The second section will make an exploratory spatial analysis of the Brazilian logistics sector in order to understand in detail the local pattern and its relation with the other sectors of the economy. The third section will show the MapLog model, capable of describing the long-term distribution of logistics activity in Brazil, followed by the fourth section that shows the main results. Finally, the fifth section shows the final considerations.

\section{Exploratory Analysis of Spatial Data: Identifying Logistics Clusters}

\subsection{Some Spatial Concentration Metrics}

The definition of spatial agglomerations is based on the choice of desirable metrics that allows us to verify the location and size of concentrations, and that can be measured using available data. Hence, we chose for this analysis: the Horizontal Cluster Locational Quotient ( $H C L Q)$ in conjunction with the Logistics Establishments Participation (LEP), the Univariate Local Moran's I $\left(I_{i}\right)$ and the Bivariate Moran's I $\left(I_{i}^{z_{1} z_{2}}\right)$.

\footnotetext{
${ }^{2}$ Although Krugman has given new life to the area of economic geography, much of his ideas and concepts have been around for a long time. To a large extent, the history of economic geography can be seen as a process that gradually unified different segments of knowledge, as demonstrated by the different names given to the scientific field (regional and urban economics, locational theory and spatial economics), all within the same theoretical framework in which the focus shifts from perfect competition to imperfect competition and market failures (FUJITA; THISSE, 2013).
} 


\subsubsection{Horizontal Cluster Locational Quotient (HCLQ) and Logistics Establishments} Participation (LEP)

The Horizontal Cluster Locational Quotient ( $H C L Q)$ takes into account the relative and absolute importance of the sector in question considering the difference between the number of employees in the sector $s$ (e.g. Logistics) located in the region $r$ (e.g., state, country or other space unit), defined as $E_{s r}$, and the expected number of employees in the same sector and in the same region when $Q L_{r}$ assumes a value equal to unity, which is the threshold for considering that the region is specialized in a given activity, the latter being represented by $\widehat{E_{s r}}$ (FINGLETON et al., 2004).

$$
H C L Q_{r}=E_{s r}-\widehat{E_{s r}}
$$

The Locational Quotient $(L Q)^{3}$ is known to be given by $L Q_{r}=\frac{E_{s r} \cdot E_{T n}}{E_{s n} \cdot E_{T r}}$, then $\widehat{E_{s r}}=\frac{E_{s n} \cdot E_{T r}}{E_{T n}}$, when $L Q_{r}=1 . E_{s r}$ and $E_{s n}$ represent the number of employees in the logistics sector $(s)$ in the region $r$ and the country $n$ respectively, while $E_{T r}$ and $E_{T n}$ represent the total employees in the regions $r$ and $n$ respectively. It is considered as the cluster indicator $H C L Q_{r}>0$.

In turn, the Logistics Establishments Participation indicator ( $L E P$ ), used by Henderson (2003) and Rivera et al. (2014) is a simple ratio between the number of firms in the logistics sector in the region $r\left(f_{r}\right)$ and the total number of logistics firms in the country $n\left(F_{n}\right)$, given by:

$$
L E P_{r}=\frac{f_{r}}{F_{n}}
$$

where $0 \leq L E P_{r} \leq 1$. It is evident that, the higher this index, the higher the concentration of logistics firms in a region. Following Rivera et al. (2014), the threshold used will be 0.1. Thus, $L E P_{r}>0.1$ will be considered a cluster. The presence of logistics agglomeration is verified by simultaneously satisfying the following condition: $H C L Q_{r}>0$ and $L E P_{r}>0.1$.

\subsubsection{Univariate Local Moran's I $\left(I_{i}\right)$}

The Moran Local indicator or LISA (Local Indicator of Spatial Association) proposed by Anselin (1995), has the capacity of capturing local patterns of spatial autocorrelation. The local Moran coefficient I $\left(I_{i}\right)$ decomposes the global indicator (I de Moran) into the local

\footnotetext{
${ }^{3}$ The Locational Quotient $(L Q)$ determines whether a region $(r)$ has the specialization of some economic activity, and does so by comparing sectoral-spatial structures. If the quotient value is greater than unity there is evidence that the region is specialized in a particular sector, in relative terms to the national context. Crocco et al. (2006) considers a threshold higher than 1, since small regions with small industrial employment and little diversified productive structure tend to overestimate the weight of a given sector for the region.
} 
contribution of each observation in four categories HH-high/high, LL-low/low, HL-high/low and LH-low/high, being expressed by:

$$
I_{i}=\frac{z_{i} \sum_{j} W_{i j} z_{j}}{\sum_{i} z_{i}^{2}}
$$

where $z$ denotes the values of the standardized interest variable, $W z$ represents the mean values of the standardized interest variable in neighbors defined according to a weighting matrix $W$ indicating how regions $i$ and $j$ are connected ${ }^{4}$ (Anselin, 1995). A reasonable proxy for cluster existence is obtained if the HH standard is confirmed where $z$ is the number of jobs in the logistics sector.

\subsubsection{Bivariate Moran's I $\left(I_{i}^{z_{1} z_{2}}\right)$}

The indicators seen so far illustrate possible areas of agglomeration, not relating the phenomenon to any type of factor or variable. With this in mind, this section will show the connection between the logistics sector and the potential users of its services. To do so, the Bivariate Moran I $\left(I_{i}^{z_{1} z_{2}}\right)$ is described below.

Let $x_{1 i}$ and $x_{2 i}$ be two variables of interest. When they are standardized, they become $z_{1 i}$ and $z_{2 i}$ respectively. Redefining the Moran Local I formula, we arrive at the bivariate indicator:

$$
I_{i}^{z_{1} z_{2}}=z_{1 i} W z_{2 i}
$$

where $W z_{2 i}$ is the spatial lag of the standard variable $z_{2 i}$. This statistics gives an indication of the degree of linear association (positive or negative) between the value for a variable in a given location $i$ and the average of another variable in neighboring locations (Anselin, 2003).

Two relations will be verified. The first takes into account the Logistics and Agriculture sectors and the second the Logistics and Manufacturing Industry sectors, where $z_{i}$ will represent the number of jobs in these sectors by region. This exercise intends to verify a possible intralogistical heterogeneity, that is, a logistics set at the service of the agricultural sector and another one focused on industrial activity.

\footnotetext{
${ }^{4}$ The spatial weight matrix (W) will use the queen criterion (degree 1 ).
} 


\subsection{Data Description}

This section uses as its data source the Annual Social Information Relation (RAIS) ${ }^{5}$ from the administrative records of the Brazilian Ministry of Labor (MTE). The sectoral and geographical breakdowns of the data allow us to draw more precise conclusions after the analysis. Data were collected on links and establishments linked to the logistics sector with a focus on freight transport between 2006 and 2015. Only in this period the CNAE 2.0 (Subsection) is available, which comprises information at a more disaggregated level. Proceeding with this choice is important because we must remove the passenger transport from the selection. Together, the subsectors shown in Table 1 make up what we call the logistics sector. The choice of these subsectors is based on Rivera et al. (2014). In addition, the space analysis unit in question takes into account the 558 Brazilian microregions. This level of observation will allow us to verify detailed changes in the organizational structure of the activity.

[Insert Table 1]

\subsection{Observing the Logistics Agglomerations}

Figure 1 shows the spatial distribution of the logistics clusters, that is, the microregions that met the condition ( $H C L Q>0$ and $L E P>0.1)$. We chose to demonstrate only the initial and final period analyzed (2006 and 2015). In 2006, the 89 clusters were almost entirely located on the south-southeast axis ( $88 \%$ of the total). In turn, in 2015 , it is possible to verify a considerable modification of the spatial pattern, in which there is the rotation of the axis towards the center-west, with an increase in participation in $17 \%$ between the period analyzed.

The previous results are reiterated by Figure 2, which refers to the Univariate Local Moran's I, with the advantage of giving more details regarding the classification of the clusters. Again, the existence of two regions classified as high-high (regions with high logistics potential surrounded by peers of the same level) is noticed. The first belongs to the southsoutheast regions and a second emergent group of the central-west region. On the other hand, the low-low regions (regions of low logistics potential surrounded by peers of the same level) are present in the north-northeast range of Brazil.

\footnotetext{
${ }^{5}$ It should be noted that the RAIS data are underestimated, since they disregard employees and firms from the informal environment. This point is a limitation of the results, given the existence of informality, especially in road transport activity.
} 
[Insert Figure 1]

[Insert Figure 2]

The following analyses verify the relation between the logistics clusters and the productive system, for which they provide their services. For that, we selected the Agricultural and Manufacturing Industry sectors ${ }^{6}$. It can be seen from Figure 3 that the highhigh relationship, which comprises microregions with high participation in logistics jobs close to regions with high participation in agricultural employment, is centered in the central-west region. It is clear that the logistics cluster present there is mostly appropriate for the activities of this sector. In addition, continuing the analysis, and observing the causality between logistics activities and the manufacturing industry, reported in Figure 4, it is possible to verify the high-high grouping (i.e. agglomerations of logistics activities surrounded by industrial activities), centered in the south-southeast region, indicating a possible link to provide a specialized service industry.

[Insert Figure 3]

[Insert Figure 4]

This piece of information reveals that the locational decision of the logistics activity presents different motivating factors, that is, logistics firms focused on the service of the agricultural sector will tend to be located in areas of greater concentration of this activity. Such reasoning is also valid for the industrial case. The empirical evidence shown in this section will be used as an assumption in the mathematical modeling about the future spatial distribution of the logistics sector for the Brazilian case.

\section{$3 \quad$ Modeling}

\subsection{Description of the Logistics Potential Mapping Model (MapLog)}

MapLog describes an economy consisting of the agricultural, industrial and logistics sectors. The latter is segmented in the logistics sector focused on agriculture and on

\footnotetext{
6 The sectorial classification is based on the National Classification of Economic Activity (CNAE 2.0). See http://www2.sefaz.to.gov.br/consultas/cnae arquivos/CNAE\%202.0\%20Subclasses\%20-

20Estrutura\%20detalhada.pdf.

At this point, RAIS data were again adopted, but this time for jobs in the agricultural and industrial sectors. We know the limitations of the data, especially for the agricultural sector, whose informality is significant. However, the spatial and temporal disaggregation of the data leads us to use them. To learn more about the data, visit http://portalfat.mte.gov.br/wp-content/uploads/2016/02/Nota-T\%C3\%A9cnica-MTE-2014.pdf.
} 
industry ${ }^{7}$. This division is necessary, given the empirical evidence found in section 2, which has confirmed the existence of differentiated spatial dynamics of the logistics service sector depending on the demand sector. It is assumed that the locational decision of the logistics sector will be dependent on the locational choice of agriculture and industry. Ultimately, the spatial distribution of the logistics sector will be determined, that is, "pulled" by the migratory movement of agriculture and industry workers. Such a hypothesis seems plausible, since the logistics service sector works in the wake of the productive sectors. This idea is aligned with the industrialist trend that argues that services play a subordinate role in relation to the productive sectors and alone could not induce economic development (BAUMOL, 1967; FUCHS, 1968; WALKER, 1985; GERSHUNY, 1978; GERSHUNY; MILES, 1983; COHEN; ZYSMAN, 1987; MCKEE, 1988; ECALLE, 1989).

The analysis will then start from the demanding sectors of logistics services, generally characterized as agriculture and industry, in order to show the organizational evolution of their areas of occurrence, that is, where the spatial agglomerations occur. Based on this piece of information, it will be possible to check the long-term spatialization of the logistics sector. The existence of economies of scale creates spatial heterogeneity, including the real wage differential between regions. Workers (and simultaneously consumers) are attracted to regions with higher wage levels than the system average. In turn, companies are attracted to these regions, leading to the fall in the price level and consequent increase in real wages, and this is the case. It is noticed that the agglomeration process is related to economic and population concentration. Such a process is self-reinforcing, that is, circular and cumulative. Logistics clusters follow these vectors of centripetal forces.

The MapLog structure will be composed of six blocks of equations, namely: (i) regional product, (ii) nominal wage, (iii) price index, (iv) real wage, (v) migrant flow of workers and (vi) regional logistics potential.

\section{Block 1 - Regional Product}

The regional product $\left(Y_{r}\right)$ given by the expression (5) is the result of the sum of the nominal yields from the industry $\left[\mu \lambda_{r} w_{r}^{M}\right]$ and the agriculture $\left[(1-\mu) \phi_{r} w_{r}^{A}\right]$.

\footnotetext{
7 In this section, we read the industrial sector as a synonym of Manufacturing Industry, and the agricultural sector will be equivalent to Agriculture.
} 


$$
Y_{r}=\mu \lambda_{r} w_{r}^{M}+(1-\mu) \phi_{r} w_{r}^{A}
$$

Block 2 - Price Index

The second component is the price indices of industrial and agricultural goods. In the case of industrial goods, $\left(G_{r}^{M}\right)$, it follows the expression (6) dependent on the participation of the industrial workers $\left(\lambda_{s}\right)$ and the industrial nominal wage $\left(w_{s}^{M}\right)$ in the regions, the cost of transportation type iceberg between the regions $\left(T_{s r}^{M}\right)$ and the substitution elasticity for industrial goods $(\sigma)$. The last two are constants over time.

$$
G_{r}^{M}=\left[\sum_{s} \lambda_{s}\left(w_{s}^{M} T_{s r}^{M}\right)^{1-\sigma}\right]^{1 / 1-\sigma}
$$

In turn, the price level for agricultural goods $\left(G_{r}^{A}\right)$ given by expression (7) follows the notion presented in the previous paragraph. However, it is oriented towards agriculture, where $\phi_{s}$ represents the participation of farmers and $w_{s}^{A}$ is the average nominal yield in the other regions $s$. Assume an iceberg transport cost for agricultural goods $\left(T_{s r}^{A}\right)$ and constant substitution elasticity given by $\eta$.

$$
G_{r}^{A}=\left[\sum_{s} \phi_{s}\left(w_{s}^{A} T_{s r}^{A}\right)^{1-\eta}\right]^{1 / 1-\eta}
$$

The constants $T_{s r}^{M}$ and $T_{s r}^{A}$ are known to represent the ratio between the quantity of product delivered and the product received. Then $T_{s r}^{M}, T_{s r}^{A} \geq 0$, and the closer to 0 , the less the waste. These reasons are relevant parts in the calculation of the cost of transport. Empirically, because of data unavailability, it is difficult to establish an adequate value for these constants. Thus, the following proxies, described by equations (8) and (9), were established:

$$
\begin{aligned}
& T_{s r}^{M}=\tau^{M} d_{r s} \\
& T_{s r}^{A}=\tau^{A} d_{r s}
\end{aligned}
$$

where $\tau^{M}$ and $\tau^{A}$ are limited exogenous constants in a range between 0 and 1 and given the interregional distances. The greater $d_{r s}$, the greater $T_{s r}^{M}$ and $T_{s r}^{A}$ will be. The proxy seems

\footnotetext{
${ }^{8}$ In the illustrative case of two regions, we have:

(region 1) $\ldots Y_{1}=\mu \lambda_{1} w_{1}^{M}+(1-\mu) \phi_{1} w_{1}^{A}$

(region 2) $\ldots Y_{2}=\mu \lambda_{2} w_{2}^{M}+(1-\mu) \phi_{2} w_{2}^{A}$

${ }^{9}$ In the illustrative case of two regions, we have:

(region 1) $\ldots G_{1}^{M}=\left[\lambda_{1}\left(w_{1}^{M} T_{11}^{M}\right)^{1-\sigma}+\lambda_{2}\left(w_{2}^{M} T_{21}^{M}\right)^{1-\sigma}\right]^{1 / 1-\sigma}$

(region 2) $\ldots G_{2}^{M}=\left[\lambda_{1}\left(w_{1}^{M} T_{12}^{M}\right)^{1-\sigma}+\lambda_{2}\left(w_{2}^{M} T_{22}^{M}\right)^{1-\sigma}\right]^{1 / 1-\sigma}$

where $\lambda_{1}+\lambda_{2}=1$

${ }^{10}$ In the illustrative case of two regions, we have:

(region 1) $\ldots G_{1}^{A}=\left[\phi_{1}\left(w_{1}^{A} T_{11}^{A}\right)^{1-\eta}+\phi_{2}\left(w_{2}^{A} T_{21}^{A}\right)^{1-\eta}\right]^{1 / 1-\eta}$

(region 2) $\ldots G_{2}^{A}=\left[\phi_{1}\left(w_{1}^{A} T_{12}^{A}\right)^{1-\eta}+\phi_{2}\left(w_{2}^{A} T_{22}^{A}\right)^{1-\eta}\right]^{1 / 1-\eta}$

where $\phi_{1}+\phi_{2}=1$
} 
reasonable. Therefore, it is expected that the greater the distance traveled in the transport of the load, the greater the probability of losses. For the Brazilian case, we consider that $\tau^{A}>$ $\tau^{M}$, indicating that the waste in the transport of agricultural products is greater when compared to the case of industrial goods. Due to its relevance and presence in the Brazilian context, the road modal will be chosen; this includes interregional distance information.

\section{Block 3 - Nominal wage}

From the Dixit-Stiglitz model, it is possible to deduce the nominal wage for the industrial case $\left(w_{r}^{M}\right)$ as (10):

$$
w_{r}^{M}=\left[\sum_{s} Y_{s} T_{r s}^{M^{1-\sigma}} G_{s}^{M^{\sigma-1}}\right]^{1 / \sigma}
$$

And, similarly, the nominal wage for the agricultural sector $\left(w_{r}^{A}\right)$ follows (11):

$$
w_{r}^{A}=\left[\sum_{s} Y_{s} T_{r s}^{A^{1-\eta}} G_{s}^{A^{\eta-1}}\right]^{1 / \eta}
$$

The components in the equations have already been listed in the previous blocks.

\section{Block 4 - Real wage}

The industrial (12) and agricultural (13) real wages are derived from the deduction of the nominal wage by the price index (cost of living).

$$
\begin{gathered}
\omega_{r}^{M}=w_{r}^{M}\left(G_{r}^{M}\right)^{-\mu}\left(G_{r}^{A}\right)^{\mu-1} \\
\omega_{r}^{A}=w_{r}^{A}\left(G_{r}^{M}\right)^{-\mu}\left(G_{r}^{A}\right)^{\mu-1}
\end{gathered}
$$

\section{Block 5 - Migration}

Through this block, we insert the dynamics in the model given by the spatial change of workers and farmers (i.e., migration process), which is influenced by real wage differentials,

\footnotetext{
11 In the illustrative case of two regions, we have:

(region 1) $\ldots w_{1}^{M}=\left[Y_{1}\left(T_{11}^{M}\right)^{1-\sigma}\left(G_{1}^{M}\right)^{\sigma-1}+Y_{2}\left(T_{12}^{M}\right)^{1-\sigma}\left(G_{2}^{M}\right)^{\sigma-1}\right]^{1 / \sigma}$

(region 2) $\ldots w_{2}^{M}=\left[Y_{1}\left(T_{21}^{M}\right)^{1-\sigma}\left(G_{1}^{M}\right)^{\sigma-1}+Y_{2}\left(T_{22}^{M}\right)^{1-\sigma}\left(G_{2}^{M}\right)^{\sigma-1}\right]^{1 / \sigma}$

12 In the illustrative case of two regions, we have:

(region 1) $\ldots w_{1}^{A}=\left[Y_{1}\left(T_{11}^{A}\right)^{1-\eta}\left(G_{1}^{A}\right)^{\eta-1}+Y_{2}\left(T_{12}^{A}\right)^{1-\eta}\left(G_{2}^{A}\right)^{\eta-1}\right]^{1 / \eta}$

(region 2) $\ldots w_{2}^{A}=\left[Y_{1}\left(T_{21}^{A}\right)^{1-\eta}\left(G_{1}^{A}\right)^{\eta-1}+Y_{2}\left(T_{22}^{A}\right)^{1-\eta}\left(G_{2}^{A}\right)^{\eta-1}\right]^{1 / \eta}$

13 In the illustrative case of two regions, we have:

(region 1) $\ldots \omega_{1}^{M}=w_{1}^{M}\left(G_{1}^{M}\right)^{-\mu}\left(G_{1}^{A}\right)^{\mu-1}$

(region 2) $\ldots \omega_{2}^{M}=w_{2}^{M}\left(G_{2}^{M}\right)^{-\mu}\left(G_{2}^{A}\right)^{\mu-1}$

${ }^{14}$ In the illustrative case of two regions, we have:

(region 1) $\ldots \omega_{1}^{A}=w_{1}^{A}\left(G_{1}^{M}\right)^{-\mu}\left(G_{1}^{A}\right)^{\mu-1}$

(region 2) $\ldots \omega_{2}^{A}=w_{2}^{A}\left(G_{2}^{M}\right)^{-\mu}\left(G_{2}^{A}\right)^{\mu-1}$
} 
thus changing the values of the variables $\lambda_{r}$ and $\phi_{r}$ over time. The dynamics assumed closely follows Fujita et al. (1999), and will be given by

$$
\begin{aligned}
& \lambda_{r(t)}=\lambda_{r(t-1)}+\chi^{M}\left(\omega_{r(t)}^{M}-\bar{\omega}_{(t-1)}^{M}\right) \\
& \phi_{r(t)}=\phi_{r(t-1)}+\chi^{A}\left(\omega_{r(t)}^{A}-\bar{\omega}_{(t-1)}^{A}\right)
\end{aligned}
$$

The definition of the locational dynamics of workers in the industrial (14) and agricultural (15) sectors will ultimately indicate the location of the demanding sectors of logistics services.

\section{Block 6 - Logistics Potential}

Now, it remains to be seen how the logistics industry will behave. As already stated, the logistics sector will follow the spatial movement of the productive sectors. In this way, the market potential calculation will be used, whose determinants are the shares of industrial and agricultural workers $\left(\lambda_{s}\right.$ and $\phi_{s}$ respectively) and the inverse distance $1 / d_{r s}$. The expressions follow Isard et al. (2017) and are given by (16) and (17)

$$
\begin{aligned}
& \Omega_{r}^{T_{M}}=\sum_{s} \frac{1}{d_{r s}} \lambda_{s} \\
& \Omega_{r}^{T_{A}}=\sum_{s} \frac{1}{d_{r s}} \phi_{s}
\end{aligned}
$$

$\Omega_{r}^{T_{M}}$ and $\Omega_{r}^{T_{A}}$ are the market potential for firms in the logistics sector focused on industry and agriculture, respectively.

\footnotetext{
15 In the illustrative case of two regions, we have: (region 1) $\ldots \lambda_{1(t)}=\lambda_{1(t-1)}+\chi^{M}\left(\omega_{1(t)}^{M}-\bar{\omega}_{(t-1)}^{M}\right)$ $\left(\right.$ region 2) ... $\lambda_{2(t)}=\lambda_{2(t-1)}+\chi^{M}\left(\omega_{2(t)}^{M}-\bar{\omega}_{(t-1)}^{M}\right)$ where, $\bar{\omega}_{(t-1)}^{M}=\left(\omega_{1(t-1)}^{M}+\omega_{2(t-1)}^{M}\right) / 2$

${ }^{16}$ In the illustrative case of two regions, we have: $\left(\right.$ region 1) $\ldots \phi_{1(t)}=\phi_{1(t-1)}+\chi^{A}\left(\omega_{1(t)}^{A}-\bar{\omega}_{(t-1)}^{A}\right)$ (region 2) ... $\phi_{2(t)}=\phi_{2(t-1)}+\chi^{A}\left(\omega_{2(t)}^{A}-\bar{\omega}_{(t-1)}^{A}\right)$ where, $\bar{\omega}_{(t-1)}^{A}=\left(\omega_{1(t-1)}^{A}+\omega_{2(t-1)}^{A}\right) / 2$

${ }^{17}$ In the illustrative case of two regions, we have: (region 1) $\ldots \Omega_{1}^{T_{M}}=\lambda_{1}+\frac{1}{d_{12}} \lambda_{2}$ (region 2) $\ldots \Omega_{2}^{T_{M}}=\frac{1}{d_{12}} \lambda_{1}+\lambda_{2}$

${ }^{18}$ In the illustrative case of two regions, we have: (region 1) $\ldots \Omega_{1}^{T_{A}}=\phi_{1}+\frac{1}{d_{12}} \phi_{2}$ (region 2) $\ldots \Omega_{2}^{T_{A}}=\frac{1}{d_{12}} \phi_{1}+\phi_{2}$
} 


\subsection{Empirical Implementation}

The MapLog model was calibrated using data provided by national statistical agencies and from other studies. The model is simulated for 50 years, from 2015 onwards, and has as its spatial scope the 27 federative units of Brazil, composed of 26 states and 1 federal district. The equations that make up the six blocks of the model received a temporal dynamics and were log-linearized, aiming to reduce the computational effort. Thus, the values of the endogenous variables in steady-state will be null, and the results of the projections will be given in log-deviation ${ }^{19}$.

The purpose of our simulation exercises is to analyze the long-term logistics market potentials that arise from the locational decisions of the demanding sectors of their services, i.e. agriculture and industry. To do so, the simulations follow predefined scenarios. Table 2 summarizes the scenarios adopted in the computational simulations. The key parameters of the model are: substitution elasticity for industrial $(\sigma)$ and agricultural goods $(\eta)$, the locational sensitivity of agricultural and industrial labor to real wage deviations $\left(\chi^{A}\right.$ and $\chi^{M}$, respectively) of $\tau^{A}$ and $\tau^{M}$ present in the calculation of the cost of transportation of agricultural and industrial goods. Based on a baseline scenario (BS), sensitivity tests (ST) were performed to observe the behavior of the results. Below we find their description:

$B S: \sigma=2.079 ; \eta=1.720 ; \chi^{A}=\chi^{M}=0.10 ; \tau^{A}=0.60 ; \tau^{M}=0.30$

ST.1: variation of the parameters $\sigma$ and $\eta(+0.2), \chi^{A}$ and $\chi^{M}(+0.05)$ and $\tau^{A}$ and $\tau^{M}(+0.2)$.

ST.2: variation of the parameters $\sigma$ and $\eta(-0.2), \chi^{A}$ and $\chi^{M}(-0.05)$ and $\tau^{A}$ and $\tau^{M}(-0.2)$.

ST.3: variation of the parameters $\chi^{A}$ and $\chi^{M}(+0.05)$, all other parameters being equal.

ST.4: variation of the parameters $\chi^{A}$ and $\chi^{M}(-0.05)$, all other parameters being equal.

ST.5: variation of the parameters $\tau^{A}$ and $\tau^{M}(+0.2)$, all other parameters being equal.

ST.6: variation of the parameters $\tau^{A}$ and $\tau^{M}(-0.2)$, all other parameters being equal.

ST.7: variation of the parameters $\sigma$ and $\eta(+0.2)$, all other parameters being equal.

ST.8: variation of the parameters $\sigma$ and $\eta(-0.2)$, all other parameters being equal.

[Insert Table 2]

19 The simulations were performed using MATLAB. The code is available upon request. 


\section{$4 \quad$ Results: Spatial projection of the logistics sector}

\subsection{Spatial distribution of the logistics-industry sector}

Figure 5 shows the recent locational distribution of the logistics sector focused on industry (referring to the year 2015) and the results of the computational simulations following the scenario and the sensitivity tests shown in the previous section (referring to the year 2065). Figure 5a shows that, for the year 2015, the logistic-industrial sector is concentrated mostly in the south-east region, in the states of São Paulo (SP), Minas Gerais (MG), Rio de Janeiro (RJ), Paraná (PR), Santa Catarina (SC) and Rio Grande do Sul (RS).

Figure $5 b$ shows the projections for 2065 , about the spatial distribution of the logistics sector focused on industry, based on the baseline scenario. It should be emphasized that, in this model, the logistics sector operates in the wake of the productive sectors and shows the following systematics: centripetal forces and centrifugal forces act on the regions stimulating the movement of the workers inserted in the productive sectors resulting in some regions that are benefited and others that are not. In search of a demanding market, the logistics sector follows this dynamic. Thus, changes in the locational pattern of the logistics sector will be identical to those of the productive sectors that demand their services. In this scenario, we can observe a change in the locational axis of the sector, in which most of the Midwest, North and Northeast regions of Brazil receive a larger number of firms in this sector. It should be noted that these regions showed a greater deviation from the others, that is, they grew above average during this period (2015-2065), which does not mean that the South-Southeast region is no longer important. This result indicates a possible trajectory of convergence of the access to the logistics sector focused on industry. Therefore, logistics activities directed to the industrial sector are spreading across the Brazilian territory, or rather, regions with low level of access to the logistic-industrial services are growing east to have access to higher rates compared to regions with high access to the service. Thus, the gap between regions in terms of access to this type of logistical service is reduced over the period analyzed.

In order to understand how sensitive the results are to the values of the key parameters, the analysis continues, performing the appropriate sensitivity tests (ST's) described above. The results obtained with ST.1 to ST.8 that change the values of the key parameters (i.e., $\sigma, \eta, \chi^{A}, \chi^{M}, \tau^{A}$ and $\tau^{M}$ ) are shown in Figures $5 c$-j. It can be seen that these 
maps are identical to the base scenario, so that it is possible to state that the results found in the base scenario are consistent.

This subsection showed a conclusive result of the MapLog model. Taking into account the baseline scenario (and corroborated by the sensitivity tests), we can observe a change within five decades of the locational pattern of the logistics sector focused on industry in Brazil, indicating a process of spatial convergence of access to this service. The states of Paraná (PR), Santa Catarina (SC), Mato Grosso (MT), Mato Grosso do Sul (MS), Goiás (G0), Tocantins (TO), Ceará (CE) and Piauí (PI) are highlighted in relation to the others.

[Insert Figure 5]

\subsection{Spatial Distribution of the Logistics Sector for Agriculture}

This subsection is intended to discuss the results found on the spatial distribution of the logistics sector focused on agriculture (see Figure 6). The recent scenario, shown in Figure $6 \mathrm{a}$, depicts the access to logistics-agricultural services for the year 2015. The sector is concentrated in São Paulo (SP), Minas Gerais (MG), Paraná (PR), Rio Grande do Sul (RS), Mato Grosso (MT), Mato Grosso do Sul (MS) and Goiás (GO).

On the other hand, the simulation base scenario (see Figure 6b) shows the long-term spatial perspective of the logistic-agricultural sector, that is, of five decades. The regions benefited, i.e., that had greater log-deviations of the potential logistics variable, are practically the same ones that already show a concentration of the sector, with emphasis in the regions of São Paulo (SP) and Minas Gerais (MG). It is possible to state that there is no ongoing process of spatial convergence of access to logistics services for agriculture. Or rather, the regions that already have access to the service had log-deviation superior to regions lacking or with little access.

Again, to check the consistency of the model, sensitivity tests were carried out to follow the description already discussed above. The results obtained are not similar to those for the logistic-industrial case (see Figure $6 c-j$ ), that is, there is no sensitivity of the results to the key parameters of the model. In general, based on the baseline scenario, there appears to be no spatial convergence of access to logistics services for agriculture. In this case, centripetal forces appear to be more relevant than centrifugal components, acting in the direction of cluster conservation. 
[Insert Figure 6]

\section{Conclusion}

The main purpose of this work was to investigate the recent and long-term spatial distribution of the logistics sector in Brazil. In other words, the work was aimed at identifying in the literature factors that explain the location of logistics firms and search through mathematical modeling to project the spatial evolution of the sector. To achieve this goal, the Logistics Potential Mapping Model (MapLog) was constructed, which follows the theoretical tradition of the New Economic Geography (NEG). MapLog is composed of six blocks, namely: regional product, nominal wage, price index, real salary, migrant flow of workers and regional logistics potential, and brings some innovations in relation to the traditional Core-Periphery model, the main one being the insertion of the logistics sector, which specifically addresses the agricultural and industrial sectors.

Two points deserve to be highlighted. First, the results point to a change within five decades of the locational pattern of the logistics sector focused on industry in Brazil, indicating a process of spatial convergence of access to this service. The states of Paraná (PR), Santa Catarina (SC), Mato Grosso (MT), Mato Grosso do Sul (MS), Goiás (GO), Tocantins (TO), Ceará (CE) and Piauí (PI) are highlighted in relation to the others. In contrast, there appears to be no spatial convergence of access to logistical services for agriculture. The regions benefited, that is, that had greater log-deviations of the potential logistics variable, are practically the same ones that already show a concentration in the sector. Therefore, the states of São Paulo and Minas Gerais stand out.

Second, the MapLog model proved to be effective in that it brought results indicating the regions where the logistics sector will intensify its activities over the next few years, thus putting pressure on the local transport infrastructure. At this moment, it is a digression on the model. MapLog starts from an analysis of the spatial concentration of demanding sectors of the logistics sector, and based on this information, we were able to build a simple expression that indicates the logistics potential of the regions of analysis. Thus, these results serve as an action guide for policy makers linked to the transport and infrastructure sectors.

Although this methodological application allowed us to reach the initial objective of analyzing the present and long-term spatial distribution of the logistics sector in Brazil, 
advances and extensions can be approached, mainly in terms of details and disaggregation, such as:

1. Consider smaller spatial units, such as microregions or municipalities. In this way, migratory movements can be seen with greater clarity. In addition, it should be emphasized that intra-regional dynamics may show behavior different from its higher level; e.g., microregions that increased the logistical-industrial or logistical-agricultural potential in federative units that showed declining participation, or vice versa. For this reason, the reduction of the space observation unit is recommended as a future research proposal.

2. The disaggregation of the logistics sector and the insertion of other demanding sectors (e.g. trade).

3. Throughout this work, we made the assumption that the logistics firms were able to place their choice of vehicles in the productive sectors. Future work may alter this hypothesis by moving toward a logistics sector closer to the sources of consumption - that is, more connected to the end of the supply chain.

4. Adopt alternative ways of calculating the logistics market potential.

\section{References}

Anselin, L. (1995). Local Indicators of Spatial Association - LISA. Geographical Analysis, 27(2), 93-115.

Anselin, L. (2003). Spatial Externalities, Spatial Multipliers, and Spatial Econometrics. International Regional Science Review, 26(2), 153-166.

Ballou, R. H. (1985). Business Logistics Management: planning and control. London: Prentice Hall.

Baumol, W. J. (1967). Macroeconomics of unbalanced growth: the anatomy of urban crisis. The American Economic Review, 415-426.

Baumol, W. J. (1985). Information technology and the service sector: a feedback process? Philadelphia: Fishman-Davidson Center for the Study of the Service Sector, the Wharton School, University of Pennsylvania.

Bhatnagar, R., \& Sohal, A. S. (2005). Supply chain competitiveness: measuring the impact of location factors, uncertainty and manufacturing practices. Technovation, 25(5), 443-456.

Brewer, A. M., Button, K. J., \& Hensher, D. A. (2008). Handbook of logistics and supply-chain 
management. London: Emerald Group Publishing Limited.

Button, K. (2010). Transport economics. Cheltenham, UK: Edward Elgar Publishing.

Capello, R. (2009). Space, growth and development. Handbook of Regional Growth and Development Theories, 33-52.

Capello, R., \& Nijkamp, P. (2009). Introduction: regional growth and development theories in the twenty-first century--recent theoretical advances and future challenges. Handbook of Regional Growth and Development Theories. Massachusetts: Edgar Elgar Publishing.

Chopra, S., \& Meindl, P. (2003). Gerenciamento da Cadeia de Suprimentos: Estratégia, Planejamento, e Operação. New York: Pearson Prentice Hall.

Cohen, S. S., \& Zysman, J. (1987). Why manufacturing matters: The myth of the post-industrial economy. California Management Review, 29(3), 9-26.

Combes, P., Mayer, T., \& Thisse, J. (2008). Economic geography: The integration of regions and nations. New Jersey: Princeton University Press.

Crocco, M. A., Galinari, R., Santos, F., Lemos, M. B. \& Simões, R. (2006). Metodologia de identificação de aglomerações produtivas locais. Nova Economia, 16, 211-241.

Dixit, A. K., \& Stiglitz, J. E. (1977). Monopolistic Competition and Optimum Product Diversity. American Economic Review, 67(3), 297-308.

Dubey, V. (1977). Definição de economia regional. In Economia Regional. Belo Horizonte: Editora UFMG.

Ecalle, F. (1989). L'Économie des services. Paris: Presses universitaires de France.

Fingleton, B., Igliori, D. C., \& Moore, B. (2004). Employment growth of small high-technology firms and the role of horizontal clustering: Evidence from computing services and R\&D in Great Britain, 1991-2000. Urban Studies, 41(4), 773-799.

Fuchs, V. R. (1968). The Service Economy. New York: National Bureau of Economic Research.

Fujita, M., Krugman, P., \& Venables, A. J. (1999). The Spatial Economy: Cities, Regions, and International Trade. Southern Economic Journal (Vol. 67). Cambridge: Mit Press.

Fujita, M., \& Thisse, J. (2013). Economics of agglomeration: cities, industrial location, and globalization. New York: Cambridge University Press. 
Gershuny, J. (1978). After industrial society?: the emerging self-service economy. London: Macmillan.

Gershuny, J., \& Miles, I. (1983). The new service economy: the transformation of employment in industrial societies. Westport: Praeger Publishers.

Hall, D., \& Braithwaite, A. (2008). The development of thinking in supply chain and logistics management. In: Handbook of logistics and supply-chain management (pp. 81-98). UK: Emerald Group Publishing Limited.

Heaver, T. D. (2008). Perspectives on global performance issues. In Handbook of Logistics and Supply-chain Management (pp. 11-28). Emerald Group Publishing Limited.

Henderson, J. V. (2003). Marshall's scale economies. Journal of Urban Economics, 53(1), 1-28.

Hugos, M. H. (2011). Essentials of supply chain management (Vol. 62). New York: John Wiley \& Sons.

Isard, W., Azis, I. J., Drennan, M. P., Miller, R. E., Saltzman, S., \& Thorbecke, E. (2017). Methods of interregional and regional analysis. New York: Taylor \& Francis.

Krugman, P. (1991). Increasing returns and economic geography. Journal of Political Economy, 99(3), 483-499.

Krugman, P. (1998a). Space: the final frontier. The Journal of Economic Perspectives, 12(2), 161-174.

Krugman, P. (1998b). What's new about the new economic geography? Oxford Review of Economic Policy, 14(2), 7-17.

Krugman, P., \& Venables, A. (1996). Integration, specialization, and the adjustment. European Economic Review, 40(3-5), 959-967.

Krugman, P., \& Venables, A. J. (1995). Globalization and the Inequality of Nations. The Quarterly Journal of Economics, 110(4), 857-880.

Lemos, M. B. (2008). A Nova Geografia Econômica: uma leitura crítica. Belo Horizionte: Tese de Professor Titular (UFMG).

Losch, A. (1954). Economics of location. New Haven: Yale University Press.

McCann, P., \& Van Oort, F. (2009). Theories of agglomeration and regional economic growth: a historical review. Handbook of Regional Growth and Development Theories, 19-32. 
McKee, D. L. (1988). Growth, Development, and the Service Economy in the Third World. New York: Praeger Publishers.

Rivera, L., Sheffi, Y., \& Welsch, R. (2014). Logistics agglomeration in the US. Transportation Research Part A: Policy and Practice, 59, 222-238.

Samuelson, P. A. (1952). The transfer problem and transport costs: the terms of trade when impediments are absent. The Economic Journal, 62(246), 278-304.

Thisse, J. (2011). Geografia Econômica. In: Economia Regional e Urbana (p. 17). Rio de Janeiro: Instituto de Pesquisa Econômica Aplicada (Ipea).

Thomson, J. M. (1974). Modern transport economics. London: Penguin Education.

Walker, R. A. (1985). Is There a Service Economy? The Changing Capitalist Division of Labor. Science \& Society, 49(1), 42-83.

Waters, D. (2003). Logistics: an introduction to supply chain management. London: Palgrave Macmillan. 
Tables and Figures

Table 1 - Definition of the logistics sector

\begin{tabular}{|c|c|}
\hline $\begin{array}{c}\text { CNAE } 2.0 \\
\text { (Subclass) }\end{array}$ & Description \\
\hline $4911-6 / 00$ & Railroad transportation of goods \\
\hline $4930-2 / 01$ & Cargo transportation, except dangerous goods and removals, municipal \\
\hline $4930-2 / 02$ & $\begin{array}{l}\text { Cargo road transport, except dangerous products and removals, intermunicipal, interstate } \\
\text { and international }\end{array}$ \\
\hline $4930-2 / 03$ & Road transport of dangerous goods \\
\hline $4930-2 / 04$ & Removals company (road transport) \\
\hline $5011-4 / 01$ & Coastal shipping - Freight \\
\hline $5012-2 / 01$ & Long-sea shipping - Freight \\
\hline $5021-1 / 01$ & Inland freight transport, municipal, except crossing \\
\hline $5021-1 / 02$ & Freight transport by cargo, intermunicipal, interstate and international, except crossing \\
\hline $5030-1 / 01$ & Maritime support navigation \\
\hline $5030-1 / 02$ & Port support navigation \\
\hline $5120-0 / 00$ & Air freight transport \\
\hline $5211-7 / 01$ & General warehouses - issue of warrant \\
\hline $5211-7 / 02$ & Furniture storage \\
\hline $5211-7 / 99$ & Deposits of goods for third parties, except warehouses and furniture storage \\
\hline $5212-5 / 00$ & Loading and unloading \\
\hline $5221-4 / 00$ & Concessionaires of highways, bridges, tunnels and related services \\
\hline $5231-1 / 01$ & Port infrastructure management \\
\hline $5231-1 / 02$ & Terminal operations \\
\hline $5332-0 / 00$ & Maritime agency activities \\
\hline $5240-1 / 01$ & Operation of airports and landing fields \\
\hline $5240-1 / 99$ & Activities auxiliary to air transport, except airport operations and landing fields \\
\hline $5250-8 / 01$ & Commissioner orders \\
\hline $5250-8 / 02$ & Customs broker activities \\
\hline $5250-8 / 03$ & Freight forwarding, except for maritime transport \\
\hline $5250-8 / 04$ & Logistics organization of cargo transportation \\
\hline $5250-8 / 05$ & Multimodal transport operator - OTM \\
\hline $5310-5 / 01$ & National Mail Activities \\
\hline $5310-5 / 02$ & Activities of franchisees and permission holders of National Post Office \\
\hline $5320-2 / 01$ & Pouch services not carried out by the National Post Office \\
\hline $5320-2 / 02$ & Fast Delivery Services \\
\hline
\end{tabular}

Source: Elaborated by authors.

Table 2 - Key parameter values in the base scenario (BS) and in the sensitivity tests (ST)

\begin{tabular}{lccccccccc}
\hline Parameter & BS & ST.1 & ST.2 & ST.3 & ST.4 & ST.5 & ST.6 & ST.7 & ST.8 \\
\hline$\sigma$ & 2.079 & 2.279 & 1.879 & 2.079 & 2.079 & 2.079 & 2.079 & 2.279 & 1.879 \\
$\eta$ & 1.720 & 1.920 & 1.520 & 1.720 & 1.720 & 1.720 & 1.720 & 1.920 & 1.520 \\
$\chi^{A}$ & 0.10 & 0.15 & 0.05 & 0.15 & 0.05 & 0.10 & 0.10 & 0.10 & 0.10 \\
$\chi^{M}$ & 0.10 & 0.15 & 0.05 & 0.15 & 0.05 & 0.10 & 0.10 & 0.10 & 0.10 \\
$\tau^{A}$ & 0.60 & 0.80 & 0.40 & 0.60 & 0.60 & 0.80 & 0.40 & 0.60 & 0.60 \\
$\tau^{M}$ & 0.30 & 0.50 & 0.10 & 0.30 & 0.30 & 0.50 & 0.10 & 0.30 & 0.30 \\
\hline
\end{tabular}

Note: The symbols present in the table can be described as: $\sigma$-elasticity of substitution for industrial goods; $\eta$-elasticity of substitution for agricultural goods; $\chi^{A}$ - locational sensitivity of agricultural labor to deviations in real wages; $\chi^{M}$ - locational sensitivity of industrial labor to deviations in real wage; $\tau^{A}$ - value used in the constant of losses in the transport of agricultural goods $\left(T_{r s}^{A}\right)$ and $\tau^{M}$ - value used in the constant of losses in the transport of industrial goods $\left(T_{r s}^{M}\right)$.

Source: Elaborated by authors. 
Figure 1 - Cluster Map (HCLQ $>0$ and $L E P>0.1)$

(a) 2006

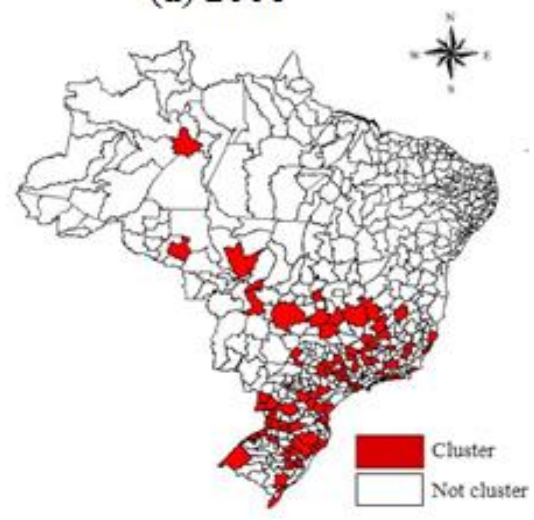

(b) 2015

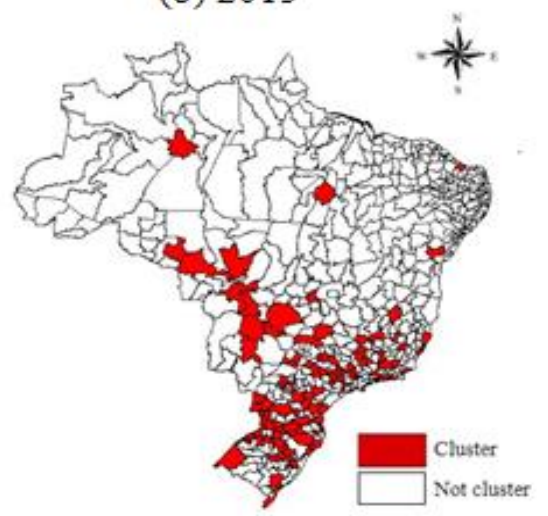

Source: Elaborated by authors.

Figure 2 - Cluster map (LISA) for participation in logistics jobs*

(a) 2006

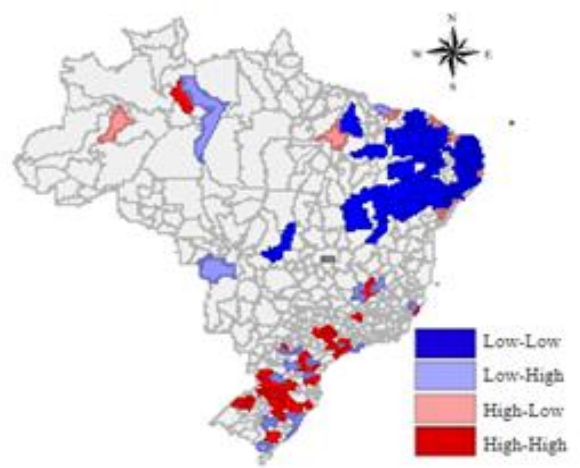

(b) 2015

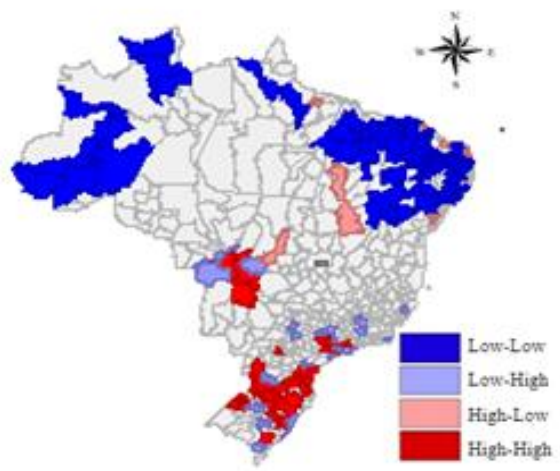

Note: * The spatial weight matrix (W) will use the queen criterion (degree 1).

Source: Elaborated by authors.

Figure 3 - Bivariate map for job participation in logistics and agriculture*

(a) 2006

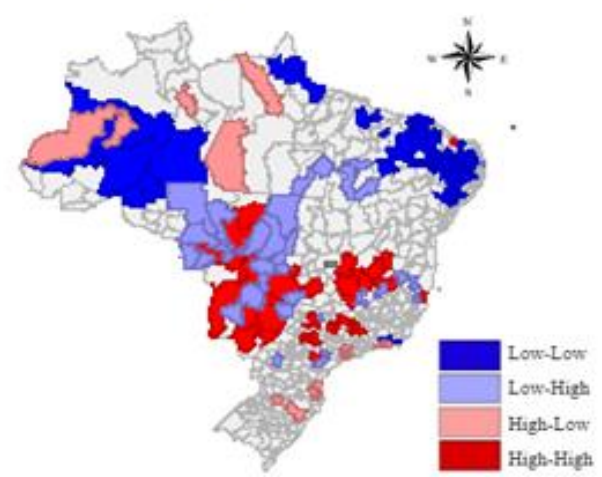

(b) 2015

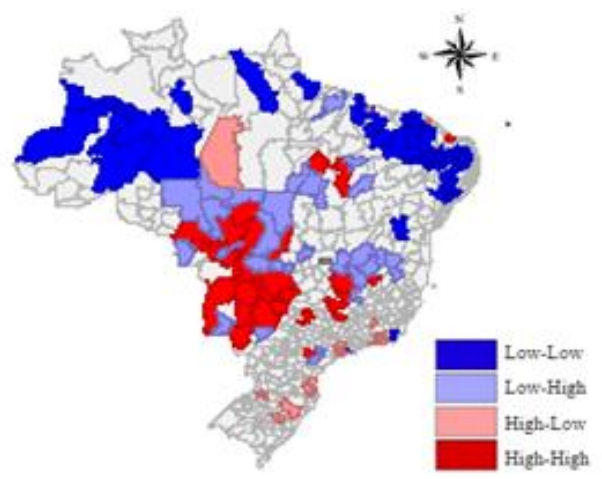

Note: ${ }^{*}$ The spatial weight matrix (W) will use the queen criterion (degree 1).

Source: Elaborated by authors. 
Figure 4 - Bivariate map for job participation in logistics and manufaturing industry*

(a) 2006

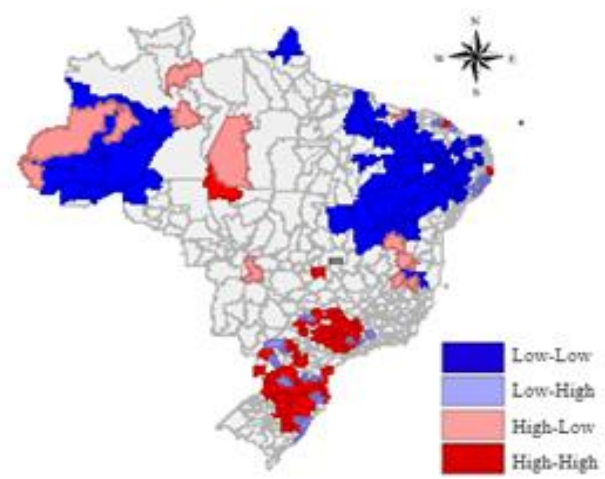

(b) 2015

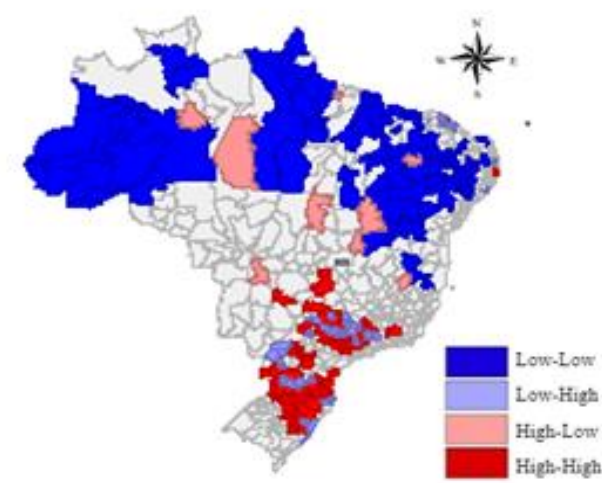

Note: ${ }^{*}$ The spatial weight matrix (W) will use the queen criterion (degree 1).

Source: Elaborated by authors. 
Figure 5 - Potential for Logistic-Manufaturing Industry sector, current scenario (2015) and projections (2065), for federative units of Brazil, according to model MapLog*

(a) Current (2015)

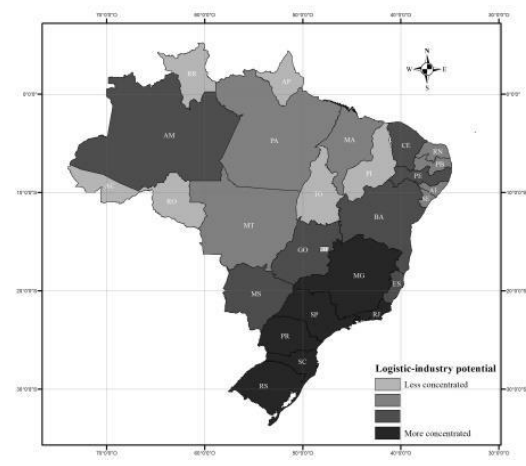

(f) ST.4

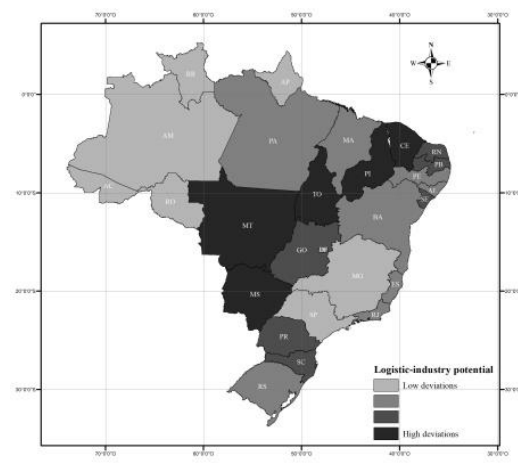

(b) BS

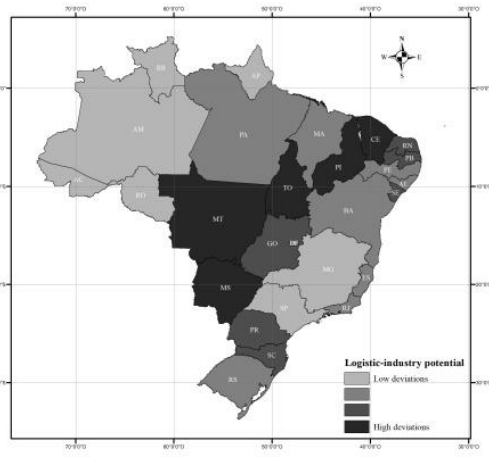

(g) ST.5

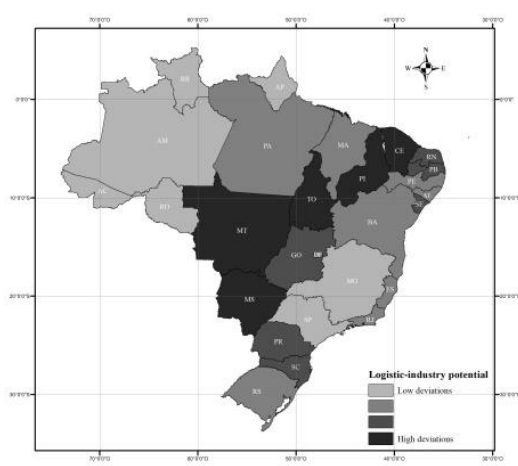

(c) ST.1

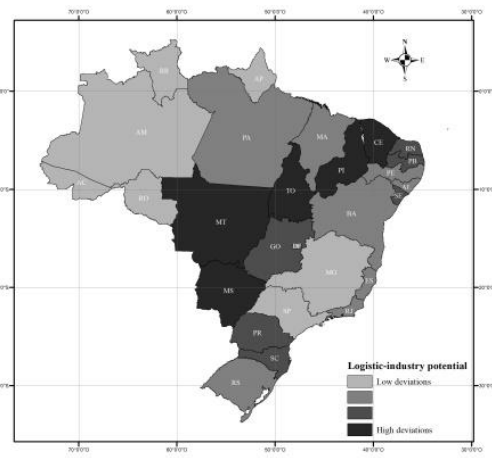

(h) ST.6

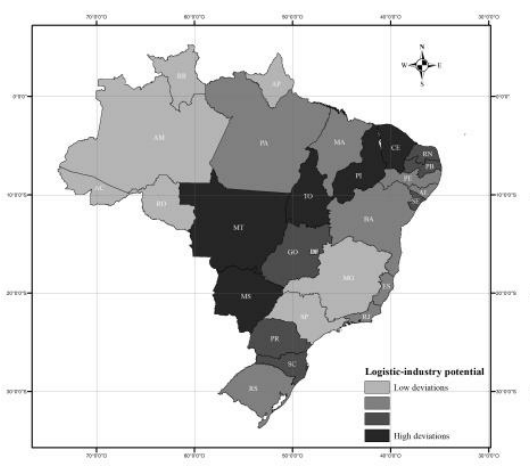

(d) ST.2

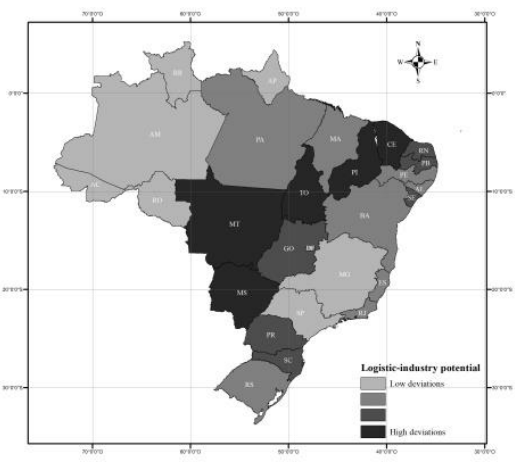

(i) ST.7

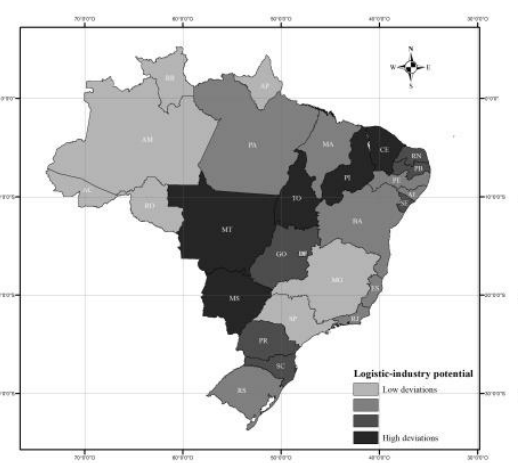

(e) ST.3

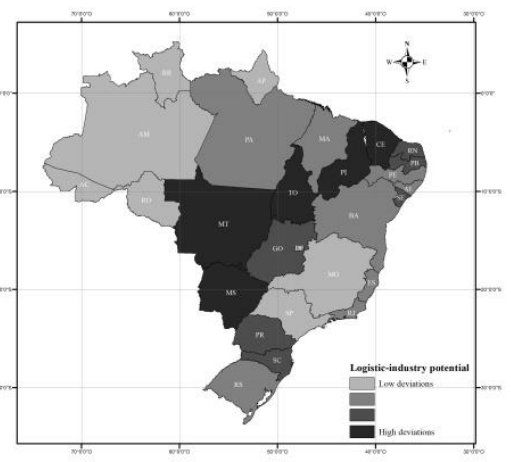

(j) ST.8

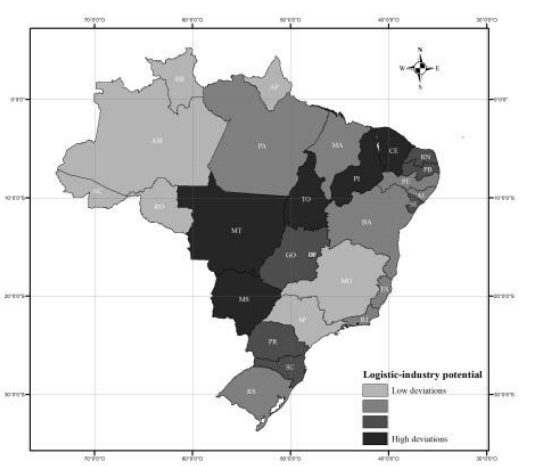

Source: Elaborated by authors.

* Note: Figure (a) current scenario; (b) long-term situation using base scenario; (c) positive variation of all key parameters; (d) negative variation of all key parameters; (e) positive variation of the parameters $\chi^{A}$ and $\chi^{M}$; (f) negative variation of the parameters $\chi^{A}$ and $\chi^{M}$; (g) positive variation of the parameters $\tau^{A}$ and $\tau^{M}$; (h) negative variation of the parameters $\tau^{A}$ and $\tau^{M}$; (i) positive variation of the parameters $\sigma$ and $\eta$ and (j) negative variation of the parameters $\sigma$ and $\eta$. 
Figure 6 - Potential for Logistic-Agricultural sector, current scenario (2015) and projections (2065), for federative units of Brazil, according to model MapLog*

(a) Current (2015)

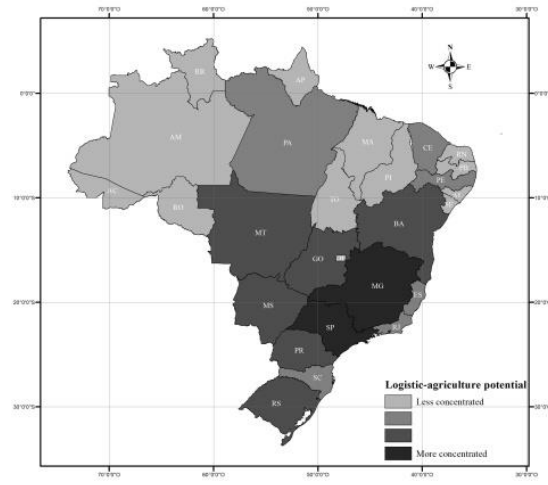

(f) ST.4
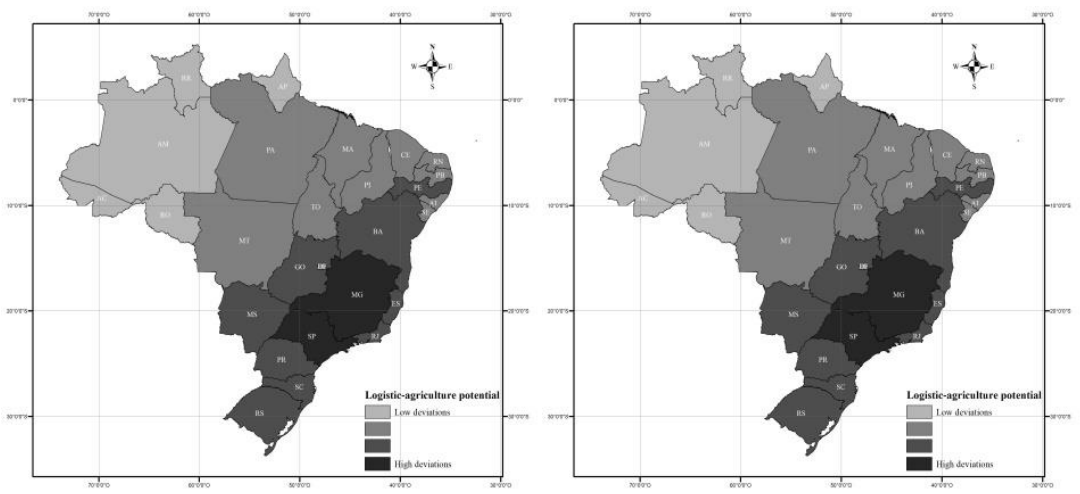

(b) BS

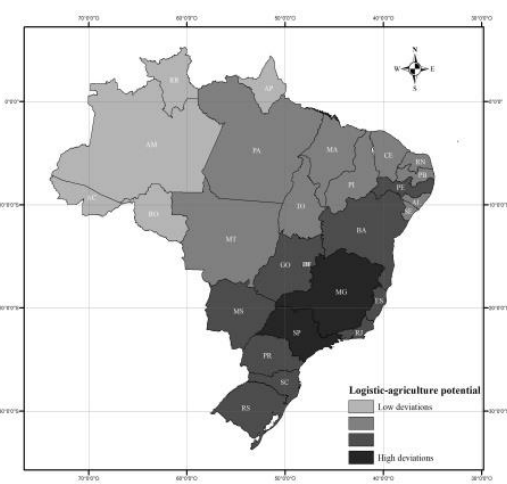

(g) ST.5
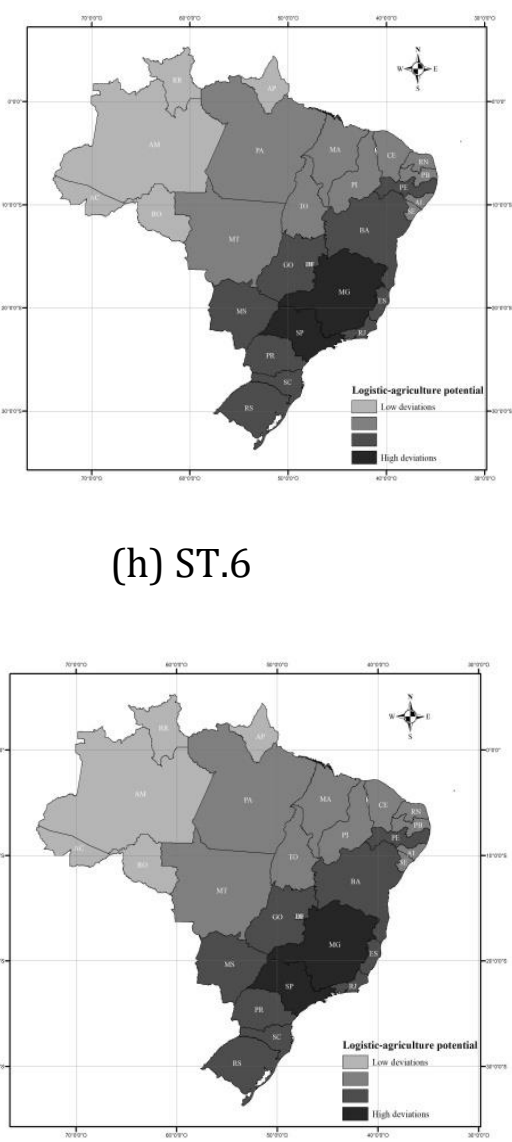

(h) ST.6 (d) ST.2

(i) ST.7
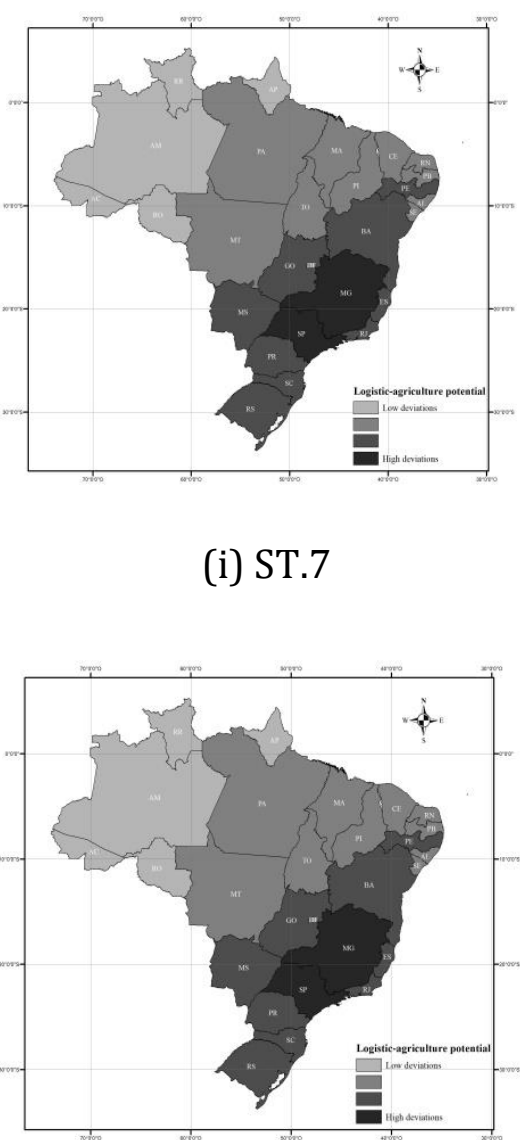

(e) ST.3

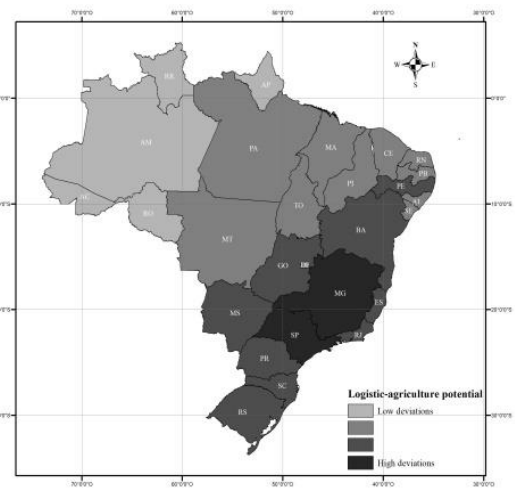

(j) ST.8

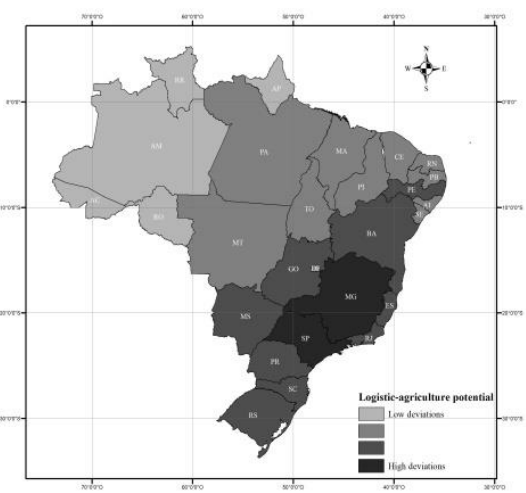

Source: Elaborated by authors.

* Note: Figure (a) current scenario; (b) long-term situation using base scenario; (c) positive variation of all key parameters; (d) negative variation of all key parameters; (e) positive variation of the parameters $\chi^{A}$ and $\chi^{M}$; (f) negative variation of the parameters $\chi^{A}$ and $\chi^{M}$; (g) positive variation of the parameters $\tau^{A}$ and $\tau^{M}$; (h) negative variation of the parameters $\tau^{A}$ and $\tau^{M}$; (i) positive variation of the parameters $\sigma$ and $\eta$ and (j) negative variation of the parameters $\sigma$ and $\eta$. 